\title{
Socio-economic inequalities in overweight among adults in Turkey: a regional evaluation
}

\author{
Isil Ergin ${ }^{1, *}$, Hur Hassoy ${ }^{1}$ and Anton Kunst ${ }^{2}$ \\ 'Department of Public Health, School of Medicine, Ege University, Bornova, 35100 Izmir, Turkey: ${ }^{2}$ Department \\ of Public Health, Academic Medical Centre (AMC), University of Amsterdam, Amsterdam, The Netherlands
}

Submitted 5 January 2011: Accepted 22 June 2011: First published online 23 August 2011

\begin{abstract}
Objective: Patterns of socio-economic inequalities in obesity and overweight have not been documented for Turkey. The present study aimed to describe educational and wealth-related inequalities for overweight in Turkey, taking a regional perspective. Design: Cross-sectional self-reported data of the World Health Survey 2002 for Turkey were used. BMI $\geq 25 \cdot 00 \mathrm{~kg} / \mathrm{m}^{2}$ was considered as overweight. Respondents were classified according to education years and a wealth score derived from the availability of household assets. Logistic regression analysis was applied to assess the relationship between overweight and socio-economic factors. Analyses were stratified by sex and region (West, Mediterranean, Middle, Black Sea and East).

Setting: Turkey.

Subjects: Among the respondents 20 years and older, 3790 women and 4057 men had data on self-reported height and weight.

Results: Age-adjusted overweight prevalence was $48 \cdot 4 \%$ for women and $46 \cdot 1 \%$ for men. For men, education was not systematically related to overweight while overweight was significantly increased among the highest wealth groups. For women, the prevalence of overweight was highest for low-educated and middlewealth groups. The size of the inequalities in overweight showed only small regional variations. In the East, however, overweight prevalence was more related to higher socio-economic position than in the other regions.

Conclusions: Socio-economic inequalities for overweight in Turkey are at a similar level as in most European countries, and especially comparable to Southern Europe. The smaller inequalities in the East correspond to the low level of socio-economic development in this part of the country. Prevention of overweight should focus on lower educational groups throughout the entire country and especially on low-educated women.
\end{abstract}

The wealth of a nation affects overweight prevalence, its distribution among different socio-economic groups and the size of these inequalities ${ }^{(1-3)}$. With excess body weight being related to a range of major non-communicable diseases, socio-economic differences in overweight could contribute strongly to broader socio-economic inequalities in health. Assessing inequalities in overweight is therefore essential for the formulation of policies to tackle noncommunicable diseases and to reduce inequalities in health.

A landmark review in 1989 concluded that high socioeconomic status (SES) was positively related to obesity in developing countries, which was in contrast to the situation in developed countries ${ }^{(4)}$. The generalizability of this view has been disputed since then, as studies from some developing countries have shown important increases in obesity among lower socio-economic groups ${ }^{(2,5,6)}$.
Attention has been called to the nutrition transition and the changing lifestyle in the rapidly growing urban populations of developing countries ${ }^{(7)}$. International overviews based on available nationally representative data (generally data from Demographic Health Surveys, DHS) have recently indicated that belonging to the lower SES group confers a strong protection against obesity in lowerincome countries, but is associated with increased risk for obesity in upper-middle-income countries. However, social inequalities for obesity do not emerge at a uniform pace among all countries ${ }^{(8-11)}$ and the onset of this shift occurs differently for the two sexes ${ }^{(3)}$.

However, there is limited availability of nationally representative data for several parts of the world. Turkey is an exemplary case. This country has nationally representative data for obesity prevalence rates derived from epidemiological studies of metabolic syndrome, CVD or 
diabetes ${ }^{(12,13)}$. However, socio-economic inequalities in obesity have not been mapped for Turkey. Studies on educational, income and regional inequalities have concentrated on maternal and child health issues ${ }^{(14,15)}$. However, given the advancement of the epidemiological and nutrition transitions, obesity and other non-communicable diseases are likely to become equally important to inequalities in mortality and morbidity in Turkey ${ }^{(16)}$.

A regional evaluation is necessary because each Turkish region represents different levels of economic development and therefore may be in a different stage of the obesity epidemic. In addition, Turkish regions differ in many other respects that may be relevant to overweight. For example, dietary patterns differ substantially among regions and there are marked regional and urban/rural differences in the degree of mobility and autonomy of women $^{(17,18)}$. Therefore, it is important to assess whether the pattern and the size of inequalities in obesity among men and women vary within the country.

The present study aimed to determine educational and wealth inequalities for overweight in Turkey, taking a regional perspective. Data from the World Health Survey (WHS) for Turkey in 2002 were used. These data have two main advantages compared with previous studies: (i) they cover a large survey sample, representative for the country; and (ii) they enable socio-economic inequalities in overweight in each Turkish region to be mapped.

\section{Materials and methods}

\section{Data}

WHS 2002 country data for Turkey were used in the present study. Household face-to-face surveys were used for the data collection in Turkey. Permission to use the official data of WHS and to perform the study was given by the WHO. Household questionnaire and individual questionnaire data ${ }^{(19)}$ are used herein.

The database of WHS combined information from individual and household questionnaires. Among the 11479 people in the individual questionnaire database, 263 who did not match with the household database were excluded. Respondents 20 years and older were selected for analysis.

\section{Variables}

In the WHS, five Turkish regions were distinguished: West, Mediterranean, Middle, Black Sea and East. Using the socio-economic development scores for cities developed by Turkish State Planning Organization ${ }^{(20)}$ the regions were found to differ strongly. If ' 1 ' represents the most developed group of cities in various terms and ' 5 ' the least developed, region West is at $1 \cdot 73$, Mediterranean is at $2 \cdot 88$, Middle is at 3.09 , Black Sea is at 3.50 and East is at 4.65 .

Education was queried as years of education in the WHS questionnaire. The years have been grouped as $0-4$,
5-7, 8-10 and $11+$ years, considering that primary education takes five years, secondary education takes three more years, while the completion of higher levels of education takes at least another three years.

For household wealth, questions on household assets were used. Ownership of eleven items associated with wealth was queried in the WHS: stereo system, washing machine for clothes, washing machine for dishes, vacuum cleaner, refrigerator, fixed line telephone, mobile/cellular telephone, computer, access to the Internet, subscriptions to magazines and/or newspaper, and a security system in the home. For the present study, the responses given on each of these eleven items were scored as 0 (does not have the item) or 1 (has the item) and these scores were summed to define the total household wealth score for each respondent. Some respondents had missing data for one or more of the items. In these cases, the scoring was adjusted by the factor 11 /number of items answered. The wealth scores have been grouped as 8-11 (highest), 6-7 (second highest), 5 (middle), 4 (second lowest) and 0-3 (lowest). Several classifications were evaluated for the grouping of the wealth scores, with similar results. For the present analysis, we used a classification that resulted in a reasonable number of respondents in each wealth group in each region.

The characteristics of the surveyed population according to region and sex are presented in Table 1 . Among the surveyed population, $76 \cdot 6 \%$ of women and $59 \cdot 8 \%$ of men had education years below 8 years. Some $41.5 \%$ of women and $40 \cdot 2 \%$ of men belonged to wealth levels equal to or below middle. The proportion of the population with low education $(<8$ years) was highest in the East $(84 \cdot 2 \%$ for women, $65 \cdot 7 \%$ for men). The lowest wealth groups were most prevalent in the East $(23.7 \%$ for women, $24.6 \%$ for men) and least prevalent in the West (7.4\% for women, $7 \cdot 5 \%$ for men) for both sexes.

WHS data included self-reported height in centimetres and weight in kilograms. This information was used to calculate the BMI for each respondent. The respondents were classified according to BMI as underweight $\left(<18.50 \mathrm{~kg} / \mathrm{m}^{2}\right)$, normal weight $\left(18.50-24.99 \mathrm{~kg} / \mathrm{m}^{2}\right)$, overweight $\left(25 \cdot 00-29 \cdot 99 \mathrm{~kg} / \mathrm{m}^{2}\right)$ or obese $\left(\geq 30 \cdot 00 \mathrm{~kg} / \mathrm{m}^{2}\right)$. In the analyses presented herein BMI was dichotomized, with the cut-off point at BMI $=25 \cdot 00 \mathrm{~kg} / \mathrm{m}^{2}$. In the present paper, $B M I \geq 25 \cdot 00 \mathrm{~kg} / \mathrm{m}^{2}$ is referred to as 'overweight'. We applied standard exclusion criteria of the Oxford cohort of the European Prospective Investigation into Cancer and Nutrition (EPIC-Oxford) to exclude unlikely values of height and weight ${ }^{(21)}$. The exclusion criteria for men were height under $100 \mathrm{~cm}$ or over $213 \mathrm{~cm}$, and weight under $30 \mathrm{~kg}$. For women these were height under $100 \mathrm{~cm}$ or over $198 \mathrm{~cm}$, and weight under $20 \mathrm{~kg}$.

Among the respondents, 1249 women had missing data on self-reported weight and 2267 for height. For men, the missing data of anthropometric self-reports were 316 and 508, respectively. In total, 3790 women $(61 \cdot 4 \%)$ 
Table 1 Distribution of the surveyed population (in percentage of the total population) according to sex, socio-economic indicator and region: adult respondents aged 20 years and over, World Health Survey 2002, Turkey

\begin{tabular}{|c|c|c|c|c|c|c|}
\hline & West & Mediterranean & Middle & Black Sea & East & Total \\
\hline \multicolumn{7}{|l|}{ Women } \\
\hline Education group & (n 2030) & $(n 803)$ & $(n 981)$ & $(n 732)$ & $(n$ 1631) & $(n$ 6177) \\
\hline$<8$ years & 72.9 & 73.2 & 76.5 & 74.2 & 84.2 & 76.6 \\
\hline$\geq 8$ years & 27.1 & 26.8 & 23.5 & 25.8 & 15.8 & 23.4 \\
\hline Wealth group & (n 2028) & $(n 803)$ & $(n 980)$ & $(n 732)$ & $(n$ 1631) & $(n$ 6174) \\
\hline Highest & 26.6 & 23.2 & 20.3 & 20.5 & 14.1 & 21.1 \\
\hline Second highest & 42.9 & 36.2 & 36.5 & 37.6 & 31.6 & 37.4 \\
\hline Middle & 16.7 & 16.2 & 17.6 & 17.1 & 17.7 & 17.1 \\
\hline Second lowest & 6.5 & 10.7 & 10.9 & 9.7 & 12.9 & 9.8 \\
\hline Lowest & 7.4 & 13.7 & 14.7 & 15.2 & 23.7 & 14.6 \\
\hline \multicolumn{7}{|l|}{ Men } \\
\hline Education group & $(n$ 1427) & $(n 613)$ & $(n 694)$ & $(n 569)$ & $(n$ 1324) & (n 4627) \\
\hline$<8$ years & 56.3 & 62.0 & 60.7 & 51.3 & 65.7 & 59.8 \\
\hline$\geq 8$ years & 43.7 & 38.0 & 39.3 & 48.7 & 34.3 & 40.2 \\
\hline Wealth group & $(n$ 1427) & $(n 613)$ & (n 694) & $(n 568)$ & $(n$ 1324) & (n 4626) \\
\hline Highest & 27.9 & 25.9 & 20.0 & 27.1 & 13.2 & 22.2 \\
\hline Second highest & 43.9 & 38.7 & 34.3 & 35.9 & 33.0 & 37.7 \\
\hline Middle & 14.5 & 15.5 & 15.0 & 17.4 & 17.0 & 15.8 \\
\hline Second lowest & 6.2 & 8.7 & 14.8 & 8.6 & 12.2 & 9.8 \\
\hline Lowest & 7.5 & 11.3 & 15.9 & 10.9 & 24.6 & 14.6 \\
\hline
\end{tabular}

Table 2 Percentage of the surveyed population with weight and/or height unknown according to sex, socio-economic indicator and region: adult respondents aged 20 years and over, World Health Survey 2002, Turkey

\begin{tabular}{|c|c|c|c|c|c|}
\hline & West & Mediterranean & Middle & Black sea & East \\
\hline \multicolumn{6}{|l|}{ Women } \\
\hline Education group & (n 2030) & $(n$ 803) & $(n 981)$ & $(n 732)$ & $(n$ 1631) \\
\hline$<8$ years & $44 \cdot 5$ & $45 \cdot 6$ & 53.6 & $49 \cdot 9$ & $45 \cdot 3$ \\
\hline$\geq 8$ years & $11 \cdot 8$ & $10 \cdot 2$ & $15 \cdot 2$ & $10 \cdot 6$ & $9 \cdot 3$ \\
\hline Wealth group & (n 2028) & $(n 803)$ & $(n 980)$ & $(n 732)$ & $(n 1631)$ \\
\hline Highest & $23 \cdot 6$ & $18 \cdot 3$ & $23 \cdot 6$ & 20 & $20 \cdot 4$ \\
\hline Second highest & $33 \cdot 1$ & $29 \cdot 9$ & $41 \cdot 1$ & $34 \cdot 9$ & $34 \cdot 3$ \\
\hline Middle & $42 \cdot 6$ & 48.5 & 52.9 & $46 \cdot 4$ & $43 \cdot 4$ \\
\hline Second lowest & $47 \cdot 7$ & $52 \cdot 3$ & $58 \cdot 9$ & $42 \cdot 3$ & $48 \cdot 3$ \\
\hline Lowest & $66 \cdot 7$ & 55.5 & $61 \cdot 1$ & $69 \cdot 4$ & $50 \cdot 5$ \\
\hline \multicolumn{6}{|l|}{ Men } \\
\hline Education group & $(n$ 1427) & $(n 613)$ & (n 694) & $(n 569)$ & $(n$ 1324) \\
\hline$<8$ years & $15 \cdot 4$ & $16 \cdot 3$ & $18 \cdot 8$ & $16 \cdot 4$ & $17 \cdot 5$ \\
\hline$\geq 8$ years & $6 \cdot 6$ & $4 \cdot 7$ & $8 \cdot 4$ & $3 \cdot 3$ & $4 \cdot 6$ \\
\hline Wealth group & $(n$ 1427) & $(n 613)$ & $(n 694)$ & (n 568) & $(n$ 1324) \\
\hline Highest & $6 \cdot 5$ & $9 \cdot 4$ & $9 \cdot 4$ & $5 \cdot 8$ & $6 \cdot 9$ \\
\hline Second highest & $11 \cdot 7$ & $6 \cdot 3$ & $11 \cdot 8$ & $6 \cdot 4$ & $10 \cdot 1$ \\
\hline Middle & $12 \cdot 6$ & $11 \cdot 6$ & $20 \cdot 2$ & $10 \cdot 1$ & $13 \cdot 8$ \\
\hline Second lowest & $20 \cdot 2$ & 17 & $13 \cdot 6$ & $24 \cdot 5$ & $18 \cdot 6$ \\
\hline Lowest & $20 \cdot 6$ & $33 \cdot 3$ & $23 \cdot 6$ & 21 & $17 \cdot 2$ \\
\hline
\end{tabular}

and 4057 men $(87 \cdot 7 \%)$ had data available for both height and weight. The proportions missing according to wealth and education groups are presented in Table 2. Chi-square analysis revealed that the percentage of respondents with missing values varied by age, sex, education and wealth with statistical significance. The percentage was lowest for women $\left(\chi^{2}=922 \cdot 194, P<0 \cdot 001\right)$, old $\left(\chi^{2}=231 \cdot 796\right.$, $P<0 \cdot 001)$, illiterate $\left(\chi^{2}=1541 \cdot 439, P<0 \cdot 001\right)$ and lowest wealth $\left(\chi^{2}=426 \cdot 725, P<0 \cdot 001\right)$ groups. For women, the highest proportion of missing was for the lowest wealth level and the lowest education group, especially in the West and Black Sea. For men, the highest proportion was also for the lowest wealth level and the lowest education group, especially in the Mediterranean region.
In the total population, the percentage of respondents with missing height and weight was lowest in the Middle region $\left(\chi^{2}=26 \cdot 986, P<0 \cdot 001\right)$.

\section{Statistical analysis}

Prevalence rates were age standardized using the direct method. The age distribution of the Turkish population in the year of 2003 was used as the reference population ${ }^{(22)}$.

Logistic regression analysis was applied to explore the relationship of wealth or education with overweight. Control was made for age only. Regression coefficients and their standard errors were used to calculate odds ratios. Groups with the lowest SES were taken as the reference categories. 


\section{Results}

Age-adjusted prevalence rates for both sexes and each region are presented in Fig. 1. The national prevalence for overweight was $48 \cdot 4 \%$ for women and $46 \cdot 1 \%$ for men. For women, overweight prevalence rates did not show substantial regional differences and ranged from $47 \cdot 7 \%$ (Black Sea) to $49 \cdot 0 \%$ (East). The range for men was larger, going from $42 \cdot 7 \%$ (East) to $48 \cdot 9 \%$ (Mediterranean).

The prevalence rates according to household wealth and the corresponding odds ratios are presented in Table 3. Wealth-related inequalities in overweight existed for both

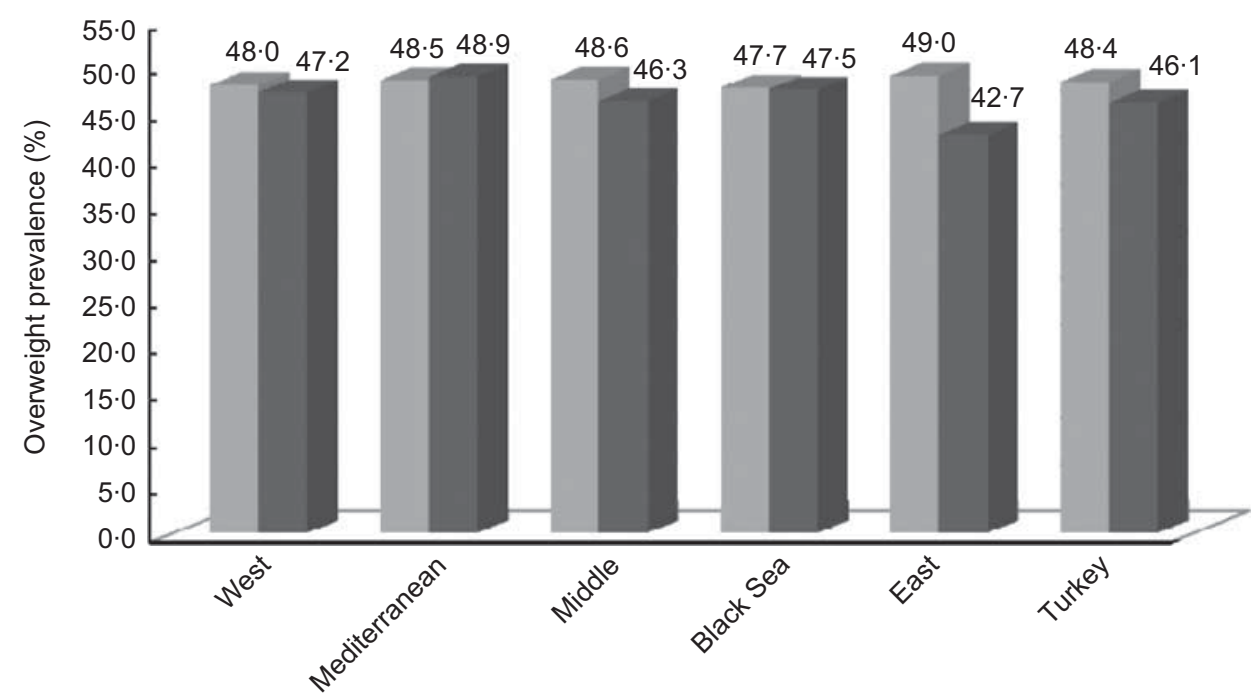

Fig. 1 Age-standardized prevalence (\%) of overweight $\left(\mathrm{BMI} \geq 25 \cdot 00 \mathrm{~kg} / \mathrm{m}^{2}\right)$ by sex ( $\square$, men; $\square$, women) and region: adult respondents aged 20 years and over, World Health Survey 2002, Turkey

Table 3 Age-standardized prevalence rates, odds ratios and $95 \%$ confidence intervals for overweight $\left(\mathrm{BMl} \geq 25 \cdot 00 \mathrm{~kg} / \mathrm{m}^{2}\right)$ according to region, wealth group and sex: adult respondents aged 20 years and over, World Health Survey 2002, Turkey

\begin{tabular}{|c|c|c|c|c|c|c|}
\hline & \multicolumn{3}{|c|}{ Women } & \multicolumn{3}{|c|}{ Men } \\
\hline & Prevalence rate (\%) & OR & $95 \% \mathrm{Cl}$ & Prevalence rate (\%) & OR & $95 \% \mathrm{Cl}$ \\
\hline \multicolumn{7}{|l|}{ West } \\
\hline Highest & $45 \cdot 97$ & $1 \cdot 14$ & $0 \cdot 60,2 \cdot 18$ & $48 \cdot 03$ & $1.94^{*}$ & $1 \cdot 17,3 \cdot 21$ \\
\hline Second highest & $49 \cdot 20$ & $1 \cdot 38$ & $0 \cdot 74,2 \cdot 60$ & $50 \cdot 20$ & $2 \cdot 00^{*}$ & $1 \cdot 23,3 \cdot 26$ \\
\hline Middle & $52 \cdot 54$ & $1 \cdot 62$ & $0 \cdot 83,3 \cdot 19$ & $47 \cdot 92$ & $1 \cdot 64$ & $0.95,2.82$ \\
\hline Second lowest & $39 \cdot 86$ & 1.09 & $0 \cdot 49,2 \cdot 40$ & $33 \cdot 67$ & 0.97 & $0.49,1.90$ \\
\hline Lowest (reference) & $41 \cdot 48$ & $1 \cdot 00$ & & $35 \cdot 02$ & $1 \cdot 00$ & \\
\hline \multicolumn{7}{|l|}{ Mediterranean } \\
\hline Highest & $39 \cdot 83$ & 1.04 & $0 \cdot 50,2 \cdot 17$ & $54 \cdot 52$ & $2 \cdot 04^{*}$ & $1 \cdot 02,4.08$ \\
\hline Second highest & $55 \cdot 22$ & $2 \cdot 18^{\star}$ & $1 \cdot 08,4 \cdot 40$ & $48 \cdot 11$ & 1.54 & $0.80,2.99$ \\
\hline Middle & $56 \cdot 07$ & $2 \cdot 62^{*}$ & $1 \cdot 14,6 \cdot 03$ & $54 \cdot 70$ & 1.99 & $0.94,4.24$ \\
\hline Second lowest & $38 \cdot 20$ & $1 \cdot 25$ & $0 \cdot 50,3 \cdot 16$ & 33.96 & $0 \cdot 87$ & $0.36,2 \cdot 09$ \\
\hline Lowest (reference) & $40 \cdot 45$ & 1.00 & & $34 \cdot 45$ & 1.00 & \\
\hline \multicolumn{7}{|l|}{ Middle } \\
\hline Highest & $46 \cdot 51$ & $1 \cdot 01$ & $0.50,2.02$ & $51 \cdot 13$ & $3 \cdot 01^{* *}$ & $1 \cdot 64,5 \cdot 52$ \\
\hline Second highest & 46.93 & 1.50 & $0.77,2.92$ & $46 \cdot 77$ & $2 \cdot 32^{\star}$ & $1.33,4.02$ \\
\hline Middle & $56 \cdot 71$ & $2 \cdot 10$ & $0.99,4.47$ & $51 \cdot 05$ & $3 \cdot 12^{\star}$ & $1 \cdot 62,6 \cdot 01$ \\
\hline Second lowest & $64 \cdot 82$ & $2 \cdot 72^{*}$ & $1 \cdot 13,6 \cdot 55$ & $42 \cdot 21$ & $1 \cdot 88$ & $0.98,3.59$ \\
\hline Lowest (reference) & $39 \cdot 17$ & $1 \cdot 00$ & & $30 \cdot 76$ & $1 \cdot 00$ & \\
\hline \multicolumn{7}{|l|}{ Black Sea } \\
\hline Highest & $44 \cdot 46$ & $1 \cdot 22$ & $0.53,2.77$ & $47 \cdot 78$ & $2 \cdot 69^{*}$ & $1 \cdot 29,5 \cdot 61$ \\
\hline Second highest & $52 \cdot 80$ & 1.92 & $0 \cdot 87,4 \cdot 21$ & $52 \cdot 62$ & $3 \cdot 05^{\star}$ & $1 \cdot 49,6 \cdot 23$ \\
\hline Middle & $49 \cdot 74$ & $1 \cdot 63$ & $0.68,3.91$ & $44 \cdot 63$ & $2 \cdot 30^{\star}$ & $1.06,4.98$ \\
\hline Second lowest & $44 \cdot 08$ & $1 \cdot 66$ & $0.63,4.38$ & $53 \cdot 34$ & $3 \cdot 69^{\star}$ & $1 \cdot 43,9 \cdot 57$ \\
\hline Lowest (reference) & $35 \cdot 96$ & 1.00 & & $25 \cdot 78$ & $1 \cdot 00$ & \\
\hline \multicolumn{7}{|l|}{ East } \\
\hline Highest & $58 \cdot 00$ & $1 \cdot 86^{\star}$ & $1 \cdot 19,2 \cdot 89$ & $56 \cdot 76$ & $3 \cdot 03^{\star *}$ & $2 \cdot 01,4 \cdot 57$ \\
\hline Second highest & $51 \cdot 38$ & $1 \cdot 50^{\star}$ & $1 \cdot 02,2 \cdot 21$ & $46 \cdot 95$ & $2 \cdot 00^{\star \star}$ & $1 \cdot 44,2 \cdot 79$ \\
\hline Middle & $50 \cdot 42$ & $1 \cdot 44$ & $0.91,2.27$ & $42 \cdot 42$ & $1 \cdot 80^{\star}$ & $1 \cdot 22,2 \cdot 66$ \\
\hline Second lowest & 44.93 & 1.09 & $0 \cdot 65,1 \cdot 82$ & $32 \cdot 11$ & $1 \cdot 04$ & $0.66,1.64$ \\
\hline Lowest (reference) & $41 \cdot 01$ & $1 \cdot 00$ & & 32.91 & 1.00 & \\
\hline
\end{tabular}

${ }^{\star} P<0.05,{ }^{* *} P<0.001$ 
Table 4 Age-standardized prevalence rates, odds ratio and $95 \%$ confidence intervals for overweight (BMI $\left.\geq 25 \cdot 00 \mathrm{~kg} / \mathrm{m}^{2}\right)$ according to region, education group and sex: adult respondents aged 20 years and over, World Health Survey 2002, Turkey

\begin{tabular}{|c|c|c|c|c|c|c|}
\hline & \multicolumn{3}{|c|}{ Women } & \multicolumn{3}{|c|}{ Men } \\
\hline & Prevalence rate (\%) & OR & $95 \% \mathrm{Cl}$ & Prevalence rate (\%) & OR & $95 \% \mathrm{Cl}$ \\
\hline \multicolumn{7}{|l|}{ West } \\
\hline$\geq 8$ years & 38.09 & $0.47^{\star *}$ & \multirow[t]{2}{*}{$0.37,0.60$} & $46 \cdot 63$ & $1 \cdot 02$ & \multirow[t]{2}{*}{$0 \cdot 80,1 \cdot 29$} \\
\hline$<8$ years (reference) & $54 \cdot 33$ & $1 \cdot 00$ & & $48 \cdot 92$ & $1 \cdot 00$ & \\
\hline \multicolumn{7}{|l|}{ Mediterranean } \\
\hline$\geq 8$ years & $37 \cdot 26$ & $0 \cdot 35^{\star *}$ & \multirow{2}{*}{$0.23,0.53$} & $50 \cdot 78$ & $1 \cdot 13$ & \multirow[t]{2}{*}{$0.79,1.63$} \\
\hline$<8$ years (reference) & $56 \cdot 89$ & $1 \cdot 00$ & & $48 \cdot 75$ & $1 \cdot 00$ & \\
\hline \multicolumn{7}{|l|}{ Middle } \\
\hline$\geq 8$ years & 33.04 & $0 \cdot 36^{\star \star}$ & \multirow[t]{2}{*}{$0.24,0.53$} & 48.05 & $1 \cdot 15$ & \multirow[t]{2}{*}{$0 \cdot 80,1 \cdot 66$} \\
\hline$<8$ years (reference) & $56 \cdot 08$ & 1.00 & & $46 \cdot 79$ & $1 \cdot 00$ & \\
\hline \multicolumn{7}{|l|}{ Black sea } \\
\hline$\geq 8$ years & $37 \cdot 81$ & $0 \cdot 47^{\star \star}$ & \multirow[t]{2}{*}{$0 \cdot 31,0 \cdot 72$} & $48 \cdot 00$ & $1 \cdot 05$ & \multirow[t]{2}{*}{$0 \cdot 72,1 \cdot 55$} \\
\hline$<8$ years (reference) & $53 \cdot 90$ & $1 \cdot 00$ & & $47 \cdot 1$ & $1 \cdot 00$ & \\
\hline \multicolumn{7}{|l|}{ East } \\
\hline$\geq 8$ years & $40 \cdot 44$ & $0.62^{*}$ & \multirow[t]{2}{*}{$0 \cdot 44,0 \cdot 87$} & $46 \cdot 37$ & $1 \cdot 20$ & \multirow[t]{2}{*}{$0.93,1.56$} \\
\hline$<8$ years (reference) & $51 \cdot 06$ & $1 \cdot 00$ & & $41 \cdot 89$ & $1 \cdot 00$ & \\
\hline
\end{tabular}

${ }^{\star} P<0.05,{ }^{*} P<0.001$.

sexes, although the results differed between the sexes. In men, in most regions, the three higher wealth groups (highest, second highest and middle) had an increased risk of overweight compared with the lowest wealth groups. The group at most risk differed by region. The East showed a regular inverse gradient, with the highest prevalence for highest wealth groups which gradually decreased towards the lowest. Similar patterns were observed for women as well. Most regions showed an inverted U-shaped pattern. For example in the Mediterranean, the middle and second highest wealth groups were at significantly higher risk (with odds ratios of $2 \cdot 62$ and $2 \cdot 18$, respectively) compared with the lowest and highest wealth groups. In the East, overweight among women steadily increased with increasing level of household wealth.

The results for education groups are presented in Table 4. Educational inequalities were more pronounced than wealth inequalities, especially for women. Table 4 shows that overweight prevalence was much lower among the high educated. However, inequalities were smaller in the East. In this region, the prevalence of overweight among high-educated women was higher than in the other regions, while the prevalence among low-educated women was lower than elsewhere. No large or statistically significant differences in overweight between education groups were observed among men. Similar patterns were observed for each region, with the East being the main exception again. This East-rest contrast in overweight (Fig. 1) was observed only among low-educated men.

\section{Discussion}

\section{Summary of findings}

In the present study, we observed a diverse pattern of socio-economic inequalities in overweight. Among women, the prevalence of overweight was increased for middlewealth groups (compared with the poorest and richest groups) and low-educated groups (compared with high educated). Among men overweight prevalence was related especially to higher household wealth, whereas no large differences were observed according to men's educational level. The pattern and size of the inequalities showed only modest regional variations, the main exception being the East region. Generally, overweight prevalence tended to be more related to higher socio-economic position in the East than in the other regions.

\section{Limitations}

Data problems that could have affected the validity of the key findings relate to the self-report of height and weight. It has been shown that people with high BMI tend to underestimate their weight and overestimate their height ${ }^{(23,24)}$. As a result, measures of relative weight based on self-reports will be biased downwards ${ }^{(25)}$. The accuracy of reporting may depend on the level of education and wealth ${ }^{(26-29)}$. There are no data for Turkey on socio-economic determinants of self-report of anthropometric measurements. However, socio-economic differences in the proportions missing (see below) warn that BMI may be underestimated especially for low socio-economic groups.

In the present study, the proportion of respondents with missing data on height or weight increased with age, low education and low wealth. This was a problem especially among women. Previous studies also found a higher proportion of missing BMI information among women and older subjects. It has also been found that failure to report weight was higher among people with high $\mathrm{BMI}^{(30)}$. As a consequence, our estimates of the prevalence of overweight may be underestimated. This implies that especially the lower educational groups or lower wealth groups may have a higher prevalence of overweight than observed herein. 
Given these potential problems, it is useful to compare our estimates of overweight prevalence with other Turkish studies. In the 2000 year of the TEKHARF (Turkish Adult Cardiovascular Risk Factor) cohort study, the prevalence of obesity (BMI $\geq 30 \cdot 00 \mathrm{~kg} / \mathrm{m}^{2}$ ) was $21 \%$ among men and $43 \%$ among women. The TOHTA (Turkish Obesity and Hypertension Study) in 2000 revealed that overweight $\left(\mathrm{BMI} \geq 25 \cdot 00 \mathrm{~kg} / \mathrm{m}^{2}\right.$ ) prevalence was $40 \%$ in men and $50 \%$ in women ${ }^{(31)}$. In the Turkish DHS, among 15-49-year-old married women, the prevalence of overweight $(\mathrm{BMI} \geq$ $25 \cdot 00 \mathrm{~kg} / \mathrm{m}^{2}$ ) was $52 \%$ in 1998 and $57 \%$ in $2003^{(14,32)}$. The prevalence rates estimated in our study ( $48 \%$ for women and $46 \%$ for men) are in the same range as the TOHTA study, but are low compared with the other studies. Even though differences can be due to differences in study design and populations, this comparison warns that the prevalence of overweight may have been underestimated in the present study.

Household assets were counted to measure levels of household wealth. The use of indicators based on household assets has been shown to be useful for mapping health inequalities ${ }^{(33)}$. For instance, current income (and derived measures such as living below poverty lines) has been found to be less adequate, compared with accumulated wealth and housing tenure, in measuring the magnitude of socio-economic inequalities in smoking ${ }^{(34,35)}$. Studies from different countries observed that, compared with current income, measures of accumulated wealth were most strongly related to the prevalence of overweight or related outcomes ${ }^{(36-38)}$. Asset-based household wealth indicators are likely to indicate cumulative prosperity, whereas income measures the purchasing power and financial situation at one moment in time only.

\section{Interpretation of variations by gender and socio-economic indicators}

The magnitude of inequalities in overweight depended on what aspect of socio-economic position we studied. Educational level usually shows the strongest relationship with overweight ${ }^{(39-41)}$. Education reflects socio-economic circumstances in youth and shapes cognitive abilities including receptivity to health education messages ${ }^{(42)}$, as well as shaping socio-economic and other opportunities of later life. When obesogenic environments trigger the onset of overweight, education may be a protective factor for those who are able to act on the knowledge about harmful effects ${ }^{(40)}$.

In previous international studies, women have been shown to have larger inequalities in overweight and obesity than men ${ }^{(39,42,43)}$. In the present study as well, we observed large educational differences in overweight prevalence among women, while no consistent differences were observed among men. This sharp gender contrast was also observed for Spain, Italy and Greece. In these countries, there is no relationship for men but a strong relationship for women, whereas the gender contrast is much weaker in other European regions $^{(3)}$. The large gender difference that we observed for Turkey thus suggests that there might be a more generalized 'Mediterranean' pattern of educational inequalities in overweight.

In Europe, a higher income is related with less overweight ${ }^{(3)}$. The gradients in Turkey are somewhat different, mainly because of the low prevalence of overweight in the poorest 20 or $40 \%$ of the population. This lower prevalence might be the result of the dietary deficiencies. The protective effect of absolute poverty against obesity was implied in earlier studies ${ }^{(44)}$. If this explanation holds, the high prevalence of overweight in middlewealth groups in Turkey suggests that these groups have moved from food shortage to a situation of abundance. Rapid urbanization and the changes introduced in food production, processing, storage and distribution all result in the nutrition transition ${ }^{(45,46)}$. As others have suggested, groups most affected by the nutrition transition are likely to be those who have just escaped from poverty ${ }^{(1,44,47)}$.

\section{Interpretation of variations by region}

The East presented a substantially different profile of socio-economic inequalities in overweight compared with the rest of the country, with a relatively low prevalence of overweight among the poor. The East of Turkey is the least developed region of the country. The terrain is highly mountainous and the most important economic activity is husbandry. The rate of population growth is low because of out-migration. Per capita income is the lowest among Turkey ${ }^{(17)}$. Infant mortality and maternal mortality are at very high levels compared with other regions ${ }^{(14,48)}$. Moreover, the military conflict in this region during the last decades has been an important barrier for development. The inverse gradients for overweight that we observed for the East correspond to its low socio-economic development and seem to reflect an earlier stage of the obesity epidemic ${ }^{(2)}$.

In Turkey, dietary patterns differ substantially between regions and specific cuisines are named regionally: Southeastern, Middle Anatolia, Black Sea and Mediterranean. Fat, fibre, fruit and vegetable consumptions in these cuisines are fairly different from each other ${ }^{(49)}$. Moreover, the availability and thus the price of certain food groups differ between regions because of geographical circumstances, agricultural opportunities and seasonal reasons ${ }^{(49)}$. For example, meat is cheaper in Middle Anatolia and East than in the West and Mediterranean, while the situation is vice versa for fruit and vegetables. Fish is the cheapest and most available food in the Black Sea region. Thus, access to some food groups may differ among regions and socio-economic groups. It has been shown previously that high intakes of fat, low intakes of fibre and low intakes of fruit and vegetables are associated with overweight ${ }^{(50)}$. The ability to afford food has been suggested to be an important factor in the socio-economic patterning of weight ${ }^{(1)}$. From this perspective, it is surprising that we did not observe 
large regional differences in the overall prevalence of overweight or in socio-economic inequalities in overweight. Additional surveys are needed on the effects of changes in food availability, food prices and dietary patterns on socioeconomic inequalities in overweight in countries such as Turkey.

Access to opportunities for physical exercise is less for women in the Middle, East and Black Sea regions. There are gender-based barriers that restrict women from leaving their homes for recreational activities. In Turkey, many decisions of women - even the decision of pregnancy is generally in the domain of men due to patriarchal ideology ${ }^{(51)}$. This ideology is less pronounced in the West and Mediterranean than in the East, Middle and North ${ }^{(17)}$. This ideology also affects women's access to education and welfare, and their enrolment in the labour market. The percentage of employed women is relatively high in the West, reaching $10 \cdot 4 \%$ employment rate, while it is as low as $2.7 \%$ in the East ${ }^{(20)}$. Moreover, conservative approaches based on religion are correlated with geographical region, where more conservative areas are located towards the East and Middle. As a result, aesthetic norms or cultural expectations with respect to weight standards may vary regionally and across different SES groups. Finally, fertility rates - important to weight gain among women - show important regional variations, with total fertility rates being close to 2 in western provinces, compared with 4 and above in more eastern provinces ${ }^{(15)}$.

Despite these large variations in potential determinants of overweight between Turkish regions, most of these regions, except the East, are highly similar regarding the overall prevalence and socio-economic inequalities in overweight. This suggests that inequalities in overweight in Turkey are mostly determined by the general socioeconomic development and urbanization - processes that have occurred in most Turkish regions except the East. More specific factors of a cultural or geographical nature seem to play only a modest role at regional level.

\section{Conclusions}

The size and pattern of the inequalities in overweight in Turkey are comparable to those of most European countries, and bear special resemblance to Southern European countries. The different patterns in the East region are likely to reflect the low socio-economic development of this part of the country. The similarities between the other regions suggest that more specific factors of a cultural or geographical nature influence overweight inequalities to only a modest extent.

The overweight inequalities being more pronounced for women has important policy implications for countries like Turkey, because women already bear large inequalities with respect to infectious diseases (i.e. tuberculosis ${ }^{(52)}$, sexually transmitted diseases ${ }^{(53)}$ ), nutritional deficiencies, maternal and perinatal conditions ${ }^{(53,54)}$. Thus, overweight inequalities will contribute to already large health inequalities among women. Prevention of obesity should focus on lower educational groups throughout the entire country and especially on low-educated women.

\section{Acknowledgements}

This research received no specific grant from any funding agency in the public, commercial or not-for-profit sectors. There are no conflicts of interest. I.E. contributed to the conception and design of the study, the acquisition of data, prepared the data set, did the data analysis, discussed core ideas, drafted the article and prepared the final manuscript. H.H. contributed to the conception and design of the study, the acquisition of data, prepared the data set and commented on the drafts. A.E. contributed to the conception and design of the study, led the project, discussed core ideas and commented on drafts. All authors read and approved the final manuscript.

\section{References}

1. Monteiro CA, Moura CE, Conde WL et al. (2004) Socioeconomic status and obesity in adult populations of developing countries: a review. Bull World Health Organ 82, 940-946.

2. Martorell R, Kettel Khan L, Hughes ML et al. (2000) Obesity in women from developing countries. Eur J Clin Nutr $\mathbf{5 4}$, $247-252$.

3. Roskam AJR, Kunst AE, Oyen HV et al. (2010) Comparative appraisal of educational inequalities in overweight and obesity among adults in 19 European countries. Int J Epidemiol 39, 392-404.

4. Sobal J \& Stunkard AJ (1989) Socioeconomic status and obesity: a review of the literature. Psychol Bull 105, 260-275.

5. Monteiro CA, Mondini L, Souza ALM et al. (1995) The nutrition transition in Brazil. Eur J Clin Nutr 49, 105-113.

6. Monteiro CA, Benicio MHDA, Conde WL et al. (2000) Shifting obesity trends in Brazil. Eur J Clin Nutr 54, 342-346.

7. Popkin BM (1994) The nutrition transition in low-income countries: an emerging crisis. Nutr Rev 52, 285-298.

8. Hedley AA, Ogden CL, Johnson CL et al. (2004) Prevalence of overweight and obesity among US children, adolescents, and adults, 1999-2002. JAMA 291, 2847-2850.

9. Maillard G, Charles MA, Thibult $\mathrm{N}$ et al. (1999) Trends in the prevalence of obesity in the French adult population between 1980 and 1991. Int J Obes Relat Metab Disord 23, 389-394.

10. Scarborough P \& Allender S (2008) The North-South gap in overweight and obesity in England. Br J Nutr 100, 677-684.

11. Winkleby MA, Kraemer HC, Ahn DK et al. (1998) Ethnic and socioeconomic differences in cardiovascular disease risk factors: findings for women from the Third National Health and Nutrition Examination Survey, 1988-1994. JAMA 280, 356-362.

12. Kozan O, Oguz A, Abaci A et al. (2007) Prevalence of the metabolic syndrome among Turkish adults. Eur J Clin Nutr 61, 548-553.

13. Satman I, Yilmaz T, Sengül A et al. (2002) Population-based study of diabetes and risk characteristics in Turkey. Results 
of the Turkish Diabetes Epidemiology Study (TURDEP). Diabetes Care 25, 1551-1556.

14. Hacettepe University, Institute of Population Studies/ Ministry of Health - Directorate of Mother and Child Health and Family Planning/State Planning Organization (2004) Turkey Demographic and Health Survey 2003. http://www.hips.hacettepe.edu.tr/tnsa2003/anaraporenglish. shtml (accessed November 2010).

15. Hacettepe University, Institute of Population Studies/ Ministry of Health - Directorate of Mother and Child Health and Family Planning/State Planning Organization (2009) Turkey Demographic and Health Survey 2008. http:// www.hips.hacettepe.edu.tr/eng/tdhs08/ar.shtml (accessed November 2010).

16. Baskent University/Ministry of Health/Refik Saydam Hygiene Center Presidency, School of Public Health (2004) National Burden of Disease and Cost Effectiveness Project - Final Report, 1st ed. http://eng.hm.saglik.gov.tr/ $\mathrm{pdf} / \mathrm{nbd} / \mathrm{raporlar} /$ burdenofdiseaseENG.pdf (accessed November 2010).

17. Hosgor AG \& Smits J (2006) The status of rural women in Turkey: what is the role of regional differences. NiCE Working Paper 06-101. http://www.ru.nl/economics/ research/nice_working_papers/\#2006 (accessed November 2010).

18. State Planning Organization (2001) Directorate General of Economical Sectors and Coordination. Report of National Food and Nutrition Strategies Study Group. Ankara: Devlet Planlama Teskilati; available at http://ekutup.dpt.gov.tr/ gida/strateji.pdf

19. World Health Organization (2010) World Health Survey. http:// www.who.int/healthinfo/survey/en/index.html (accessed November 2010).

20. Dincer B, Ozaslan M \& Kavasoglu T (2003) Socioeconomic Development Order of Provinces and Regions in Turkey. Ankara: State Planning Organization.

21. Spencer EA, Appleby PN, Davey GK et al. (2001) Validity of self-reported height and weight in 4808 EPIC-Oxford participants. Public Health Nutr 5, 561-565.

22. Turkish Statistical Institute Population Statistics (2003) Database for population census 2000, Devlet Istatistik Enstitüsü (DIE) 2003. http://tuikrapor.tuik.gov.tr/reports/rwservlet? nufus2000db2 $=\& E N V I D=$ nufus2000db2Env\&report $=$ il_koy_ sehir_cinsiyet.RDF\&p_kod $=1 \& p \_k o d=1 \&$ desformat $=\mathrm{html}$ (accessed July 2009).

23. Niedhammer I, Bugel I, Bonenfant S et al. (2000) Validity of self-reported weight and height in the French GAZEL cohort. Int J Obes Relat Metab Disord 24, 1111-1118.

24. Ziebland S, Thorogood M, Fuller A et al. (1996) Desire for the body normal: body image and discrepancies between self reported and measured height and weight in a British population. J Epidemol Community Health 50, 105-106.

25. Willett W (1998) Nutritional Epidemiology, 2nd ed. New York: Oxford University Press.

26. Gregory CO, Blanck HM, Gillespie C et al. (2008) Health perceptions and demographic characteristics associated with underassessment of body weight. Obesity (Silver Spring) 16, 979-986.

27. Lopez AD, Colin DM, Murray CJL et al. (2002) Summary Measures of Population Health: Concepts, Ethics, Measurement and Applications. Geneva: WHO.

28. Rossouw K, Senekal M \& Stander I (2001) The accuracy of self-reported weight by overweight and obese women in an outpatient setting. Public Health Nutr $\mathbf{4}$, $19-26$.

29. Dekkers JC, van Wier MF, Hendriksen IJ et al. (2008) Accuracy of self-reported body weight, height and waist circumference in a Dutch overweight working population. BMC Med Res Methodol 8, 69.
30. Ramos E, Lopes C, Oliveira A et al. (2009) Unawareness of weight and height - the effect on self-reported prevalence of overweight in a population-based study. $J$ Nutr Health Aging 13, 310-314.

31. World Health Organization (2010) Diabetes 2020, Vision and Targets: The Profile of Diabetes in Turkey - Workshop Report. Istanbul: WHO, International Diabetes Federation, Turkish Diabetes Association \& Turkish Ministry of Health; available at http://www.diyabet2020.org/getdoc/ 1283e91c-ef10-42a5-9d85-d4b45be529d/Turkiye-de-DiyabetProfili.aspx

32. Hacettepe University, Institute of Population Studies/ Ministry of Health - Directorate of Mother and Child Health and Family Planning/State Planning Organization (1999) Turkey Demographic and Health Survey 1998. Ankara: Hacettepe University, Institute of Population Studies.

33. Houweling TAJ, Kunst AE \& Mackenbach JP (2003) Measuring health inequality among children in developing countries: does the choice of the indicator of economic status matter? Int J Equity Health 2, 8.

34. Stronks K, van de Mheen HD \& Mackenbach JP (1998) A higher prevalence of health problems in low income groups: does it reflect relative deprivation? J Epidemiol Community Health 52, 548-557.

35. Schaap MM, van Agt HME \& Kunst AE (2008) Identification of socioeconomic groups at increased risk for smoking in European countries: looking beyond educational level. Nicotine Tob Res 10, 359-369.

36. Laaksonen M, Sarlio-Lähteenkorva S \& Lahelma E (2004) Multiple dimensions of socioeconomic position and obesity among employees: The Helsinki Health Study. Obes Res 12, 1851-1858.

37. Dahly DL, Larsen PG, Popkin BM et al. (2010) Associations between multiple indicators of socioeconomic status and obesity in young adult Filipinos vary by gender, urbanicity, and indicator used. J Nutr 140, 366-370.

38. Perel P, Langenberg C, Ferrie J et al. (2006) Household wealth and the metabolic syndrome in the Whitehall II study. Diabetes Care 29, 2694-2700.

39. Lindsay ML (2007) Socioeconomic status and obesity. Epidemiol Rev 29, 29-48.

40. Roskam AJ \& Kunst AE (2008) The predictive value of different socio-economic indicators for overweight in nine European countries. Public Health Nutr 11, 1256-1266.

41. Martinez JA, Kearney JM, Kafatos A et al. (1999) Variables independently associated with self-reported obesity in the European Union. Public Health Nutr 2, 125-133.

42. Singh-Manoux A, Gourmelen J, Lajnef M et al. (2009) Prevalence of educational inequalities in obesity between 1970 and 2003 in France. Obes Rev 10, 511-518.

43. Flegal KM, Harlan WR \& Landis JR (1988) Secular trends in body mass index and skinfold thickness with socioeconomic factors in young adult men. Am J Clin Nutr $\mathbf{4 8}$, 544-551.

44. Monteiro CA (2004) Obesity and inequities in health in the developing world. Int $J$ Obes Relat Metab Disord 28, 1181-1186.

45. Uusitalo U, Pietinen P \& Puska P (2002) Dietary transition in developing countries: challenges for non-communicable disease prevention. In Globalization, Diets and Noncommunicable Diseases. Geneva: WHO; available at http:// whqlibdoc.who.int/publications/9241590416.pdf

46. Chopra M (2002) Globalization and food: implications for the promotion of 'healthy' diets. In Globalization, Diets and Noncommunicable Diseases. Geneva: WHO; available at http://whqlibdoc.who.int/publications/9241590416.pdf

47. Pena M \& Bacallao J (2000) Obesity and Poverty: A New Public Health Challenge, 1st ed. Washington, DC: PAHO. 
48. Organisation for Economic Co-operation and Development (2008) OECD Reviews of Health Systems - Turkey. http:// www.oecd.org/../0,3343,en_2649_33929_42235452_1_1_1_ 1,00.html (accessed November 2009).

49. State Planning Organization, Directorate General of Economical Sectors and Coordination (2001) Report of National Food and Nutrition Strategies Study Group. http://ekutup. dpt.gov.tr/gida/strateji.pdf (accessed November 2010).

50. Giskes K, Avendano M, Brug J et al. (2010) A systematic review of studies on socioeconomic inequalities in dietary intakes associated with weight gain and overweight/obesity conducted among European adults. Obes Rev 11, 413-429.

51. Ay P, Hayran O, Topuzoglu A et al. (2009) The influence of gender roles on health seeking behaviour during pregnancy in Turkey. Eur J Contracept Reprod Health Care 14, 290-300.
52. Aksel N, Mertoglu A, Dogan H et al. (2008) Comparison of the male and female cases with pulmonary tuberculosis. Izmir Gogus Hastalıkları Hastanesi Dergisi 22, 35-45.

53. Hacettepe University, Institute of Population Studies/ Ministry of Health - Directorate of Mother and Child Health and Family Planning/State Planning Organization (2008) Turkey Demographic and Health Survey 2008 Advanced Analysis. http://www.hips.hacettepe.edu.tr/ tnsa2008/data/tnsa2008_ileri_analiz_sunumu.pdf (accessed May 2011).

54. Turkish Ministry of Health (2009) Cinsel Saglik ve Ureme Sagligi Ulusal Stratejiler Ve Eylem Plani 2005-2015 (National strategies and action plan on sexual and reproductive health 2005-2015. USEP project). http://sbu. saglik.gov.tr/tusp/turkce/yayinlar/pdf_dokumanlar/01_USEP. pdf (accessed November 2009). 